\title{
Avaliação da gordura orbitária de coelhos após enucleação e evisceração
}

\author{
Orbital fat evaluation after enucleation and evisceration in rabbits
}

\author{
Claudia Akemi Shiratori ${ }^{1}$ \\ Silvana Artioli Schellini ${ }^{2}$ \\ Mariângela E. Alencar Marques ${ }^{3}$ \\ Carlos Roberto Padovani ${ }^{4}$ \\ Carlos Roberto Pereira Padovani ${ }^{5}$
}

\footnotetext{
${ }^{1}$ Pós-graduanda da Faculdade de Medicina de Botucatu da Universidade Estadual Paulista (UNESP). Botucatu (SP).

${ }^{2}$ Livre-docente do Departamento de Oftalmologia, Otorrinolaringologia e Cirurgia de Cabeça e Pescoço da Faculdade de Medicina de Botucatu da UNESP. Botucatu (SP).

${ }^{3}$ Professor Doutor do Departamento de Patologia da Faculdade de Medicina de Botucatu da UNESP. Botucatu (SP).

${ }^{4}$ Titular do Departamento de Bioestatística da Faculdade de Medicina de Botucatu da UNESP. Botucatu (SP).

${ }^{5}$ Pós-graduando da Faculdade de Ciências Agronômicas da UNESP. Botucatu (SP).

Endereço para correspondência: Silvana A. Schellini Distrito Rubião Júnior, SN - Botucatu (SP)

CEP 18610-000

E-mail: sartioli@fmb.unesp.br

Recebido para publicação em 20.10.2004

Versão revisada recebida em 08.04.2005

Aprovação em 03.06.2005
}

\section{RESUMO}

Objetivo: Avaliar os adipócitos da gordura orbitária de coelhos após enucleação e evisceração. Métodos: Foram estudados vinte e três espécimes de gordura orbitária, provenientes de 23 coelhos com idade de 42 dias, sendo 11 submetidos à cirurgia de enucleação e 12 à evisceração. Os animais foram sacrificados 30, 90 e 180 dias após a cirurgia, avaliando-se a gordura orbitária ao microscópio óptico (aumento de 200x) e usando o programa IpWin 32. A área média celular foi calculada a partir do número de adipócitos por campo e da área de cada adipócito, tendo sido comparados os resultados dos grupos (enucleação e evisceração) usando teste estatístico não paramétrico para avaliação da área dos adipócitos. Resultados: Não houve diferença significativa entre a área média dos adipócitos quando considerado o procedimento cirúrgico (enucleação e evisceração), ou quando considerado o momento de sacrifício. Conclusão: Tendo em vista que a área dos adipócitos foi semelhante e não variou significativamente após a enucleação ou a evisceração, em período de observação de até 180 dias, a diminuição de volume orbitário que ocorre nas cavidades anoftálmicas deve ser consequiência de outros mecanismos, como mudanças na distribuição espacial da gordura da órbita.

Descritores: Tecido adiposo; Enucleação ocular; Evisceração ocular; Órbita/cirurgia; Desenho de prótese; Coelhos

\section{INTRODUÇ̃̃̃O}

A enucleação e a evisceração são técnicas cirúrgicas empregadas para a remoção do olho ou de seu conteúdo. É interessante que o paciente, após o procedimento, tenha bom aspecto estético, havendo controvérsia sobre qual delas apresentaria melhores resultados cosméticos e funcionais. $\mathrm{Na}$ evisceração, a perda de volume orbitário é menor, com menor tendência ao enoftalmo e aprofundamento do sulco palpebral superior, uma vez que a gordura, as fáscias e os ligamentos orbitários não sofrem intervenção ${ }^{(1)}$.

A longo-prazo, o portador de anoftalmia desenvolve a síndrome da cavidade anoftálmica, caracterizada por enoftalmo, aumento da profundidade e elevação do sulco palpebral superior, ptose e flacidez da pálpebra inferior ${ }^{(2)}$. A síndrome seria conseqüência da deficiência de volume do conteúdo orbitário, cuja etiopatogenia ainda não é bem compreendida. A atrofia da gordura orbitária é uma das hipóteses, aventando-se ser ela decorrente da diminuição do fluxo sanguíneo orbitário ${ }^{(3-4)}$.

A comprovação desta hipótese poderia ser feita avaliando-se os adipócitos orbitários. Assim, o objetivo deste estudo, foi avaliar experimentalmente as células gordurosas da órbita em cavidades enucleadas ou evisceradas de coelhos. 


\section{MÉTODOS}

Foi feito estudo experimental, prospectivo, avaliando-se 23 amostras de gordura orbitária, obtidas de 23 coelhos albinos da raça Norfolk, linhagem Botucatu, sendo que 11 animais foram submetidos à cirurgia de enucleação (G1) e 12, à evisceração (G2) do olho direito.

Os animais foram fornecidos pelo Biotério Central da Faculdade de Medicina de Botucatu. O estudo recebeu aprovação do Comitê de Ética em Pesquisa em Animais da Faculdade de Medicina de Botucatu para a sua realização.

Os coelhos foram anestesiados com pentobarbital sódico $3 \%$ endovenoso, na concentração de $1 \mathrm{ml} / \mathrm{kg}$ de peso e colírio de proximetacaína (Anestalcon - Allergan). Os procedimentos foram realizados seguindo as técnicas de assepsia e antissepsia.

A técnica de enucleação consistiu na peritomia límbica, isolamento dos músculos extra-oculares e desinserção dos mesmos com tesoura, secção do nervo óptico com tesoura e colher, e remoção do bulbo intacto, suturando-se a cápsula de Tenon e a conjuntiva com pontos contínuos de Mersilene 6-0 (Ethicon).

A técnica de evisceração consistiu na abertura conjuntival e corneoescleral limbar, com remoção do conteúdo ocular, hemostasia e sutura contínua da córnea e esclera e da conjuntiva usando Mersilene 6-0 (Ethicon).

Os animais foram sacrificados 30, 90 e 180 dias após a cirurgia, removendo-se fragmentos de gordura orbitária que foram fixados em formol a $10 \%$, incluídos em parafina e corados por hematoxina-eosina para exame em microscópio de luz.

Foi realizada a avaliação de parâmetros histológicos qualitativos e quantitativos. Ao exame histológico, observou-se a morfologia dos adipócitos e o padrão de distribuição dos mesmos.

A avaliação morfométrica foi feita sob aumento de 200 vezes, utilizando-se o programa IpWin 32, procedendo-se a contagem do número de células adiposas presentes por campo, de tal maneira que foram excluídos os adipócitos que se apresentaram parcialmente seccionados pela linha que delimitava o campo analisado. Foi feita também as medidas das áreas de cada adipócito, que foram somadas, obtendo-se o valor da área total.

A seguir, foi feita a razão entre os dois valores (área total/ número de adipócitos) e obtida a área média celular (Figura 1).

Foram analisados 3 campos de cada espécime.

Os resultados foram submetidos à análise estatística, comparando-se os grupos (enucleação e evisceração) nos 3 momentos de sacrifício (30, 90 e 180 dias). A avaliação foi feita sem o conhecimento prévio a que grupo pertenciam os animais.

A análise estatística dos dados foi feita por teste não paramétrico para o modelo com dois fatores, complementada com as respectivas comparações múltiplas ${ }^{(5)}$.

\section{RESULTADOS}

Ao exame histológico, a gordura orbitária apresentou o mesmo aspecto nos dois grupos experimentais.

$\mathrm{Na}$ tabela 1, apresentam-se os valores de mediana e semi- amplitude total das áreas médias celulares, comparando-se as duas cirurgias nos diferentes momentos experimentais. A análise estatística não mostrou diferença estatisticamente significativa entre a área média celular de animais submetidos à enucleação e à evisceração; também não houve diferença estatisticamente significativa em relação ao momento de sacrifício, sendo a área semelhante aos 30, 90 e 180 dias após as cirurgias $(p>0,05)$.

\section{DISCUSSÃO}

Partindo do pressuposto de que a atrofia da gordura orbitária pudesse ser a responsável pelas alterações que se estabelecem na síndrome da cavidade anoftálmica e que a manutenção do volume desempenha papel essencial na estética orbitária $^{(6)}$, foi realizada a avaliação qualitativa e quantitativa dos adipócitos em cavidades enucleadas ou evisceradas, em diferentes tempos de observação.

Esta hipótese fundamenta-se em outras observações da literatura, como a existência de uma taxa de atrofia da gordura em enxertos dermo-adiposos (variando de $10 \%, 15 \%$ e até $50 \%$ ), variações dependentes da técnica cirúrgica empregada ${ }^{(7)}$.

Porém, a metodologia utilizada não demonstrou diferença entre os dois tipos de cirurgia - a enucleação e a evisceração. Estudo semelhante também não revelou alterações no diâmetro médio e máximo de adipócitos ${ }^{(8)}$.

O tempo de observação poderia ser um fator determinante para a ocorrência de alteração das dimensões dos adipócitos. Estudo prévio relatava que mesmo no período de 210 dias após a enucleação, não havia alteração nos adipócitos de cavidades enucleadas $^{(8)}$, o que também não pudemos demonstrar com 180 dias de observação.

Uma possibilidade seria que ocorresse diminuição no número de adipócitos orbitários. Contudo, em estudo empregando a tomografia computadorizada e avaliação do crânio seco, não foi

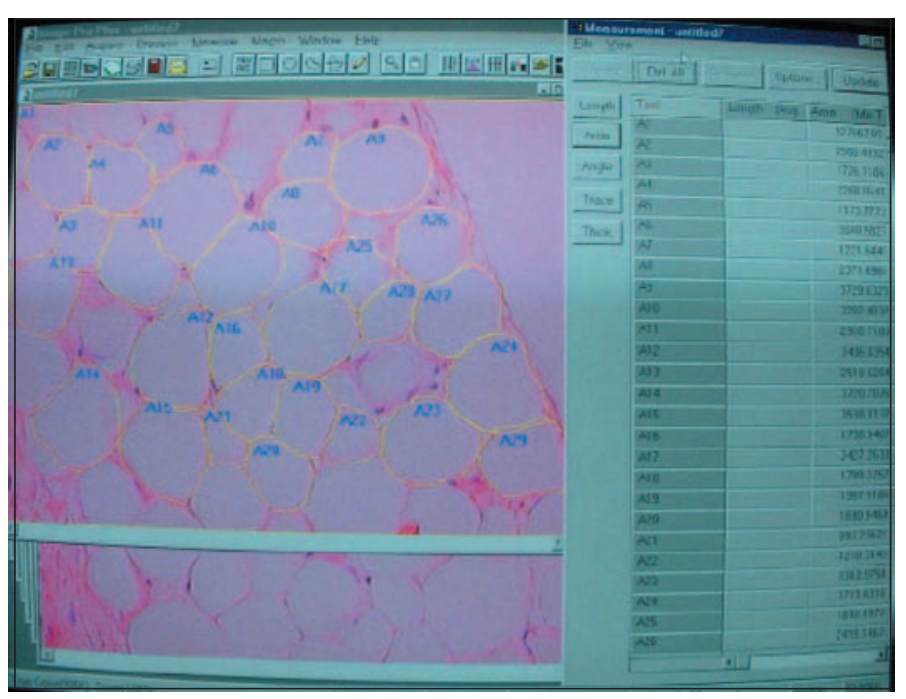

Figura 1 - Imagem dos adipócitos mensurados pelo sistema analisador de imagens 


\begin{tabular}{|c|c|c|c|c|}
\hline \multirow[t]{2}{*}{ Procedimento } & \multicolumn{3}{|c|}{ Momento de sacrifício } & \multirow{2}{*}{$\begin{array}{l}\text { Resultado do } \\
\text { teste estatístico }\end{array}$} \\
\hline & 30 dias & 90 dias & 180 dias & \\
\hline Enucleação & $43,48 \pm 8,13$ aA & $41,81 \pm 37,75$ aA & $32,46 \pm 36,79$ aA & $0,35(p>0,05)$ \\
\hline Evisceração & $29,80 \pm 6,97 a A$ & $50,61 \pm 47,82 \mathrm{aA}$ & $71,28 \pm 52,35$ aA & $5,57(p>0,05)$ \\
\hline Resultado do teste estatístico & $1,73(P>0,05)$ & $0,73(p>0,05)$ & $1,06(p>0,05)$ & \\
\hline
\end{tabular}

demonstrada correlação entre a enoftalmia e o volume de gordura orbitária em portadores de enoftalmia de diversas causas ${ }^{(9)}$.

Portanto, em cavidades enucleadas ou evisceradas, não se pode afirmar que a redução de volume que se estabelece seja causada pela atrofia da gordura orbitária. É possível que a perda de volume que se observa ao longo dos anos e que leva à síndrome da cavidade anoftálmica, seja decorrente de alterações na forma e disposição dos tecidos moles que compõem a órbita, mais do que decorrente de atrofia da gordura orbitária.

\section{CONCLUSÃO}

A área dos adipócitos de cavidades orbitárias de coelhos foi semelhante pós enucleação ou evisceração e não variou significativamente até 180 dias após a cirurgia. A diminuição de volume que ocorre nas cavidades anoftálmicas deve ser consequiência de outros mecanismos, como mudanças na distribuição espacial dos tecidos moles da órbita.

\section{ABSTRACT}

Purpose: To evaluate rabbit adipocytes of the orbital fat tissue after enucleation and evisceration. Methods: Twenty-tree specimens from 23 rabbits aged 42 days which had undergone socket surgery (evisceration and enucleation) were evaluated. The animals were sacrificed on the $30^{\text {th }}, 90^{\text {th }}$ and $180^{\text {th }}$ postoperative day. The orbital fat tissue was prepared for light microscope evaluation (magnification: 200x) and analyzed by IpWin 32 software program. The number of cells in each field and the area of each adipocyte were used to calculate the cell median area. The data were compared between the groups (enuclea- tion and evisceration) and submitted to statistical analysis by a non-parametrical test. Results: There were no statistical differences when considering the mean area of adipocytes between enucleation or evisceration or time of sacrifice. Conclusion: The volume decrease in the anophthalmic cavity is not related to orbital fat atrophy. The genesis of orbital volume reduction might result from the spacial distribution and interrelationships of the orbital soft tissue rather than changes in volume of adipocytes.

Keywords: Keywords: Adipose tissue; Eye enucleation; Eye evisceration; Orbit/surgery; Prosthesis design; Rabbits

\section{REFERÊNCIAS}

1. Schaefer DP, Della Rocca RC. Enucleation. In: Smith BC. Ophthalmic Plastic and reconstructive surgery. St Louis: Mosby; 1989. p.1278-99.

2. Silverstone PJ, Beyer-Machule CK, Schaefer DP, Della Rocca RC. Treatment of the anophthalmos and socket reconstruction. In: Smith BC. Ophthalmic plastic and reconstructive surgery. St Louis: Mosby; 1989. p.1329-59.

3. Sires BS, Lemke BN, Dorztbach RK, Gonnering RS. Characterization of human orbital fat and connective tissue. Ophthal Plast Recontr Surg. 1998; 14(6):403-14.

4. Custer P, Cook B. The team approach to the anophthalmic patient. Adv Ophthalmic Plast Reconstr Surg. 1990;8:55-7.

5. Norman GR, Streiner DL. Biostatistics: the bare essentials. St. Louis: Mosby; 1994.

6. Gola R, Carreau JP, Faissal A. [The adipose tissue of the orbit. Anatomic classification, therapeutic deductions]. Rev Stomatol Chir Maxillofac. 1995;96(3):123-36. French

7. Heher KL, Katowitz JA, Low JE. Unilateral dermis-fat graft implantation in the pediatric orbit. Ophthal Plast Recontr Surg. 1998;14(2):81-8.

8. Kronish JW, Gonnering RS, Dortzbach RK, Rankin JH, Reid DL, Phernetton TM, et al.. The pathophysiology of the anophthalmic socket. Part II: analysis of the orbital fat. Ophthal Plast Reconstr Surg.1990;6(2):88-95.

9. Carls FR, Josca R, Sailer HF. [The measurement of orbital volume in reconstruction of the orbital walls]. Minerva Stomatol. 1996;45(11):493-9. Italian.

\section{Nos artigos enviados para publicação, o nome dos autores} e suas afiliações devem estar completos. Isso facilitará a indexação e os links com as bases de dados e o CV Lates. 